\title{
FACTORS ASSOCIATED WITH DELAY IN CANCER DIAGNOSIS AND TREATMENT IN CHILDREN, A STUDY FROM NORTHERN PAKISTAN.
}

\footnotetext{
1. MBBS, FCPS (Pak), MRCP (Ireland) Professor

Department of Pediatrics CMH Lahore Medical College, Lahore, Pakistan.

2. MBBS, FCPS (Pak), MRCP (Ireland) Consultant

Department of Pediatrics Military Hospital Rawalpindi, Pakistan.

3. Medical Student Army Medical College, Rawalpindi, Pakistan.
}

Correspondence Address: Dr. Tanveer Ashraf Consultant Pediatrician Combined Military Hospital Abdul Rahman Road Lahore Cantt. Lahore.

tanveer760@gmail.com

Article received on: 04/08/2018

Accepted for publication:

14/11/2018

Received after proof reading:

25/06/2019
Tanveer Ashraf', Shoaib Ahmed ${ }^{2}$, Saman Tanveer ${ }^{3}$

ABSTRACT... This study explores various factors responsible for delay in management of Pakistani children having malignant diseases. Study Design: Cross-sectional, observational study. Setting: Pediatric Oncology Unit of Combined Military Hospital Rawalpindi. Period: $1^{\text {st }}$ March 2017 to $31^{\text {st }}$ August 2017. Material and Methods: A total of 147 children, up to 15 years of age, being managed for malignant diseases were enrolled. Data was collected by reviewing the medical record and face-to-face interviews of the parents. Time lag from onset of symptoms to start of treatment was divided in three categories, patient delay, physician delay and treatment delay. Various factors associated with delay were analyzed. Results: Out of 147 patients, 114 were male and 33 were female. Mean age was 5.76 ( \pm SD 3.15) years. Mean patient delay was 13.36 (+ SD 27.21) days. Mean physician delay was 66.22 (+ SD 87.66) days and mean treatment delay was 17.61 (+ SD 46.20) days. In 34\% of patients total delay was $>90$ days. Important factors associated with delay were age of patient, type of malignancy, financial problems, distance from healthcare facility, parents' education status, their perception about usefulness of treatment and use of alternative therapies. Patients' gender was not significantly associated with delayed management. Conclusion: One third of our patients had to wait for three months or more for definitive treatment to start. Physician delay was more than patient or treatment delay. It signifies that our health care system is not well equipped to promptly handle malignant diseases in children. Better training of medical professionals and improvement in diagnostic facilities can result in reduced time lag before definite treatment.

Key words: $\quad$ Cancer, Children, Chemotherapy, Delay, Early Diagnosis, Pakistan.

Article Citation: Ashraf T, Ahmed S, Tanveer S. Factors associated with delay in cancer diagnosis and treatment in children, a study from Northern Pakistan. Professional Med J 2019; 26(7):1156-1161.

DOI: 10.29309/TPMJ/2019.26.07.3790

\section{INTRODUCTION}

According to International Agency for Research on Cancer (IARC), childhood cancers account for $0.5-4.6 \%$ of total malignancies. ${ }^{1}$ These tumors are more responsive to chemotherapy than adult malignancies and chances of cure with proper treatment are relatively high. ${ }^{2}$ Early diagnosis is important for timely management while disease is still in its initial stages, to achieve better outcome. It is reasonable to assume that efforts to expedite the diagnosis of malignant diseases are likely to have benefits for patients in terms of survival and improved quality of life. ${ }^{3,4}$

Development of effective strategies to provide timely management of pediatric malignancies requires an understanding of factors affecting the delays and their effect on cancer prognosis. ${ }^{5}$
There are many publications regarding delay in diagnosis and treatment of childhood malignancies, but to best of our knowledge, no such studies have been published from Pakistan.

Parents are usually first individuals to notice any abnormal finding caused by malignant disorders. Their knowledge and attitude therefore becomes important in earlier presentation to a healthcare facility. Within healthcare facilities, various factors related to complexity of disease, professional expertise of the health care team and diagnostic facilities contribute to variable delay in final diagnosis. Treatment of these malignancies is a highly specialized job, possible in pediatric oncology units. There are few such facilities in developing countries and usually patients have to travel long distances to get to any of these 
centers, resulting in further delay in start of definitive treatment. $6-8$

We have grouped the causes of delay into three categories: patient delay (time since onset of symptoms to first encounter with a healthcare professional), Physician delay (time interval between first encounter with healthcare professional and confirmation of diagnosis) and treatment delay (time interval between confirmation of diagnosis and start of treatment) (Figure-1).

\section{MATERIALS AND METHODS}

This was an observational cross sectional study, conducted at Pediatric Oncology Unit of Combined Military Hospital Rawalpindi, Pakistan. A total of 147 patients up to 15 years of age, being managed for malignant diseases were enrolled in the study. Most of our patients were from Northern Punjab, Khyber Pakhtunkhwa province and Azad Jammu \& Kashmir. Parents/care givers were informed about the study and written consent was obtained. Data was collected by reviewing the medical record and face-to-face interviews of the Parents/care givers, using a questionnaire.

Time of onset of first symptom attributed to the malignant disease was asked from the parents/ caregivers. The earliest prescription after onset of above mentioned symptoms was considered the evidence of first encounter with healthcare professional to calculate patient delay. Dates of relevant laboratory reports confirming diagnosis were used to calculate Physician delay. Starting date of treatment was taken from hospital record of each patient, to calculate the treatment delay.

Data was analyzed using IBM SPSS for Windows, version 16.0. $P$ value $\leq 0.05$ was considered statistically significant at $95 \%$ confidence level.

\section{RESULTS}

A total of 147 children were included in this study, 114 were male and 33 were female. Mean age was 5.76 (standard deviation \pm 3.15 ) years.

In more than $95 \%$ of cases, patient delay was less than 30 days (mean 13.36 + SD 27.21 days).
Younger age had significant correlation with early reporting to healthcare professional. Educated mothers tend to have early consultation with the doctors ( $p$-value $<0.01$ ). Fathers' education had lesser impact on patient delay ( $p$-value > 0.05). Another important factor affecting patient delay was distance of healthcare center from patient's residence. A distance of more than 20 kilometer was associated with longer patient delay ( $p$-value $<0.05$ ). There was no significant difference in patient delay between male and female patients ( $p$-value $>0.05$ ). Families having financial problems had longer patient delay but correlation was not statistically significant. Parent's perception regarding usefulness of medical treatment of malignancies and use of alternative medicines did not affect patient delay significantly (Table-I).

Almost $45 \%$ of our patients had physician delay of more than 30 days (mean 66.22 + SD 87.66 days). Factors related to increased physician delay included increasing age, longer distance of primary healthcare centre from residence, financial problems, illiteracy or lower education level of father, use of alternate therapies (treatment by herbal medicines, homeopathy or spiritual healers) and parental perception that medical treatment is not effective in malignant diseases (Table-II). Type of malignancy also had effect on diagnostic interval. Mean diagnostic interval was longest in case of Hodgkin lymphoma and shortest in Wilms' tumor.

Once diagnosis of malignancy was confirmed, treatment started within 2 weeks in more than $80 \%$ of children. Mean treatment delay was 17.61 days (+ SD 46.20 days). Only $4 \%$ of children had treatment delay of more than one month. Factors related to increased treatment delay were older age, financial problems, more distance of pediatric oncology services from residence, use of alternate therapy like treatment by herbal medicines, homeopathy or spiritual healers. Parents' perception about usefulness of medical treatment in malignant diseases also had significant association with treatment delay. Parents who believed that cancer is curable, were more prompt to seek treatment for their child $(p$ 
value $<0.001)$ (Table-III).

Mean total time lag (interval from onset of symptoms to start of treatment) was 97.2 days (+ SD 108.15). Only $18.4 \%$ children had started treatment within one month of onset of symptoms. More than one third of patients had a total delay of $>90$ days (Table-IV).

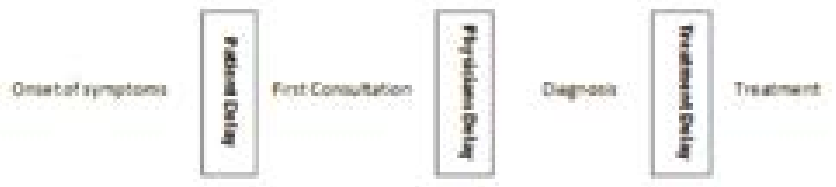

Figure-1. Different categories of delay

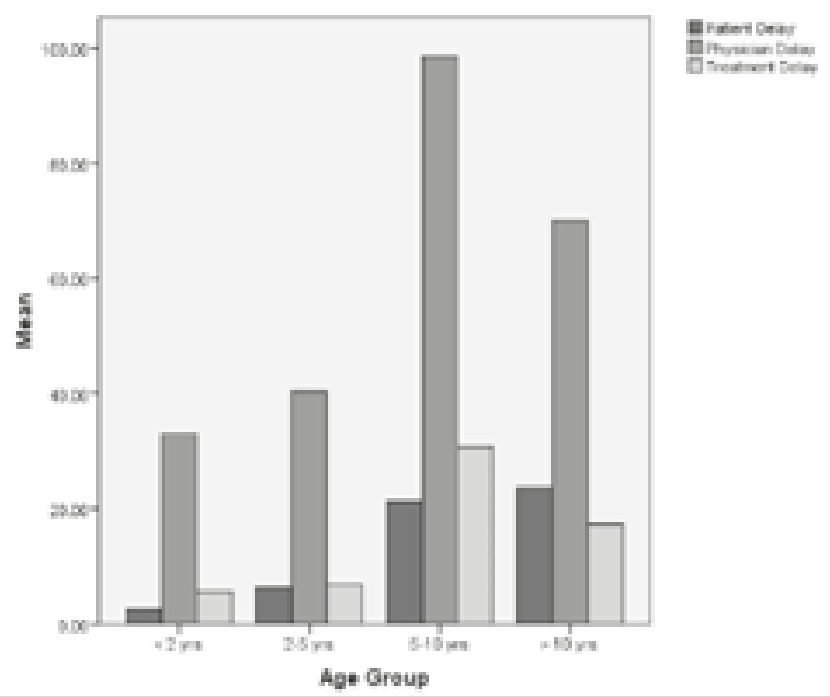

Figure-2. Mean delays (in days) in different age groups

\section{DISCUSSION}

There are many factors responsible for delay in diagnosis and treatment of children suffering from malignancies. Most of our findings are consistent with other studies published in international literature. There are however few important differences in our results. Dang-Tan and Franco reviewed 23 epidemiological studies and found that factors associated with diagnosis delays included the child's age, level of parental education, type of cancer and presenting symptoms.

One third of our patients had to wait for more than three months, before definitive treatment. Out of three categories of time lag, physician delay was significantly longer than patient or treatment delays. Mean physician delay was 66.22 days (+ SD 87.66 days) and it was $>30$ days in $45 \%$ of patients (Table-II).

\begin{tabular}{|c|c|c|}
\hline \multirow{2}{*}{$\begin{array}{l}\text { Distance to primary } \\
\text { healthcare center }\end{array}$} & Pearson Correlation & $.178^{*}$ \\
\hline & Sig. (2-tailed) & .031 \\
\hline \multirow{2}{*}{$\begin{array}{l}\text { Distance to tertiary } \\
\text { healthcare centre }\end{array}$} & Pearson Correlation & .127 \\
\hline & Sig. (2-tailed) & .126 \\
\hline \multirow{2}{*}{ Age Group } & Pearson Correlation & $.281^{\star *}$ \\
\hline & Sig. (2-tailed) & .001 \\
\hline \multirow{2}{*}{ Gender } & Pearson Correlation & -.042 \\
\hline & Sig. (2-tailed) & .617 \\
\hline \multirow{2}{*}{$\begin{array}{l}\text { Educational level of } \\
\text { father }\end{array}$} & Pearson Correlation & -.118 \\
\hline & Sig. (2-tailed) & 155 \\
\hline \multirow{2}{*}{$\begin{array}{l}\text { Educational level of } \\
\text { mother }\end{array}$} & Pearson Correlation & $-.197^{*}$ \\
\hline & Sig. (2-tailed) & .017 \\
\hline \multirow{2}{*}{$\begin{array}{l}\text { Complementary and } \\
\text { Alternative Medicine } \\
\text { (CAM) }\end{array}$} & Pearson Correlation & -.120 \\
\hline & Sig. (2-tailed) & .149 \\
\hline \multirow{2}{*}{$\begin{array}{l}\text { Parental perception } \\
\text { regarding usefulness } \\
\text { of treatment of } \\
\text { malignancy }\end{array}$} & Pearson Correlation & .045 \\
\hline & Sig. (2-tailed) & .590 \\
\hline \multirow{2}{*}{$\begin{array}{l}\text { Financial problems } \\
\text { for treatment }\end{array}$} & Pearson Correlati & -.123 \\
\hline & Sig. (2-tailed) & 137 \\
\hline
\end{tabular}

Table-I. Factors associated with patient delay

\begin{tabular}{|c|c|c|}
\hline \multirow{2}{*}{$\begin{array}{l}\text { Distance to primary } \\
\text { healthcare center }\end{array}$} & Pearson Correlation & $.188^{*}$ \\
\hline & Sig. (2-tailed) & .022 \\
\hline \multirow{2}{*}{$\begin{array}{l}\text { Distance to tertiary } \\
\text { healthcare centre }\end{array}$} & Pearson Correlation & -.006 \\
\hline & Sig. (2-tailed) & .939 \\
\hline \multirow{2}{*}{ Age Group } & Pearson Correlation & $.269^{* *}$ \\
\hline & Sig. (2-tailed) & .001 \\
\hline \multirow{2}{*}{ Gender } & Pearson Correlation & -.068 \\
\hline & Sig. (2-tailed) & .413 \\
\hline \multirow{2}{*}{$\begin{array}{l}\text { Educational level of } \\
\text { father }\end{array}$} & Pearson Correlation & $-.180^{\star}$ \\
\hline & Sig. (2-tailed) & .029 \\
\hline \multirow{2}{*}{$\begin{array}{l}\text { Educational level of } \\
\text { mother }\end{array}$} & Pearson Correlation & -.064 \\
\hline & Sig. (2-tailed) & .444 \\
\hline \multirow{2}{*}{$\begin{array}{l}\text { Complementary and } \\
\text { Alternative Medicines }\end{array}$} & Pearson Correlation & $.274^{\star \star}$ \\
\hline & Sig. (2-tailed) & .001 \\
\hline \multirow{2}{*}{$\begin{array}{l}\text { Parental perception } \\
\text { regarding usefulness } \\
\text { of treatment of } \\
\text { malignancy }\end{array}$} & Pearson Correlation & $-.318^{* \star}$ \\
\hline & Sig. (2-tailed) & .000 \\
\hline \multirow{2}{*}{$\begin{array}{l}\text { Financial problems } \\
\text { for treatment }\end{array}$} & Pearson Correlation & $-.171^{*}$ \\
\hline & Sig. (2-tailed) & .039 \\
\hline
\end{tabular}

Table-II. Factors associated with physician delay

Begum et al from Bangladesh have reported that more than $2 / 3^{\text {rd }}$ of their patients had $<30$ days of physician delay. ${ }^{14}$ In Turkey, Cecen et al found mean physician delay of 28 days in their study 
of 329 children. ${ }^{21}$ Other studies from Kenya and Uganda have reported mean physician delays of 2 and 2.6 weeks respectively. ${ }^{7}$ Comparison with other studies from developing countries signifies that our health care system is not well equipped to promptly handle malignant diseases in children. Hospital in smaller towns and remote areas lack trained medical professionals and facilities for diagnostic investigations. Parents have to take their children to tertiary care centers in large cities.

\begin{tabular}{|c|c|c|}
\hline \multirow{2}{*}{ Age in years } & Pearson Correlation & .122 \\
\hline & Sig. (2-tailed) & .143 \\
\hline \multirow{2}{*}{ Gender } & Pearson Correlation & -.139 \\
\hline & Sig. (2-tailed) & .093 \\
\hline \multirow{2}{*}{$\begin{array}{l}\text { Financial problems } \\
\text { for treatment }\end{array}$} & Pearson Correlation & -.059 \\
\hline & Sig. (2-tailed) & .477 \\
\hline \multirow{2}{*}{$\begin{array}{l}\text { Educational level of } \\
\text { father }\end{array}$} & Pearson Correlation & .093 \\
\hline & Sig. (2-tailed) & .264 \\
\hline \multirow{2}{*}{$\begin{array}{l}\text { Educational level of } \\
\text { mother }\end{array}$} & Pearson Correlation & -.028 \\
\hline & Sig. (2-tailed) & .734 \\
\hline \multirow{2}{*}{$\begin{array}{l}\text { Distance to primary } \\
\text { healthcare center }\end{array}$} & Pearson Correlation & .079 \\
\hline & Sig. (2-tailed) & .343 \\
\hline \multirow{2}{*}{$\begin{array}{l}\text { Distance to tertiary } \\
\text { healthcare centre }\end{array}$} & Pearson Correlation & -.097 \\
\hline & Sig. (2-tailed) & .243 \\
\hline \multirow{2}{*}{$\begin{array}{l}\text { Treatment by } \\
\text { Hakeem/homeopath/ } \\
\text { faith healer }\end{array}$} & Pearson Correlation & .131 \\
\hline & Sig. (2-tailed) & .114 \\
\hline \multirow{2}{*}{$\begin{array}{l}\text { Parental perception } \\
\text { regarding usefulness } \\
\text { of treatment of } \\
\text { malignancy }\end{array}$} & Pearson Correlation & -.101 \\
\hline & Sig. (2-tailed) & .222 \\
\hline
\end{tabular}

Table-III. Factors associated with treatment delay

\begin{tabular}{|l|c|c|c|c|}
\hline & Frequency & Percent & $\begin{array}{c}\text { Valid } \\
\text { Percent }\end{array}$ & $\begin{array}{c}\text { Cumulative } \\
\text { Percent }\end{array}$ \\
\hline $\begin{array}{l}<30 \\
\text { days }\end{array}$ & 27 & 18.4 & 18.4 & 18.4 \\
\hline $\begin{array}{l}31-60 \\
\text { days }\end{array}$ & 51 & 34.7 & 34.7 & 53.1 \\
\hline $\begin{array}{l}61-90 \\
\text { days }\end{array}$ & 18 & 12.2 & 12.2 & 65.3 \\
\hline $\begin{array}{l}\text { > 90 } \\
\text { days }\end{array}$ & 51 & 34.7 & 34.7 & 100.0 \\
\hline Total & 147 & 100.0 & 100.0 & \\
\hline
\end{tabular}

Table-IV. Total delay from onset of disease to start of treatment

Limited financial resources and lack of awareness about effective treatment of malignant disorders results in visits to complementary and alternative therapies. Treatment by alternate measures (herbal medicines, homeopathy or spiritual healers) results in further delay. Sixty five percent of our patients had alternate therapy before definitive medical treatment. Complementary and alternative medicine (CAM) is being used in other underdeveloped countries also. Aliyu et al from Nigeria have reported $66 \%$ patients having used CAM without informing treating physicians. ${ }^{9}$ There are many studies from developed countries about use of alternative therapies. Sanchez et al have found $30 \%$ oncology patients to use CAM in Mississippi USA whereas Singendonk et al from Netherland have reported $42 \%$ prevalence of CAM in children having malignancies. ${ }^{10,11}$

Most of modifiable factors associated with three categories of delay were common including financial problems, increased distance of well equipped healthcare centers from home town and illiteracy or lower education level of parents. Children are under care of their parents, which underscores the importance of parents' knowledge, attitudes, and behavior in the cancer diagnosis pathway. Mothers' education was related to shorter patient delay whereas fathers' education was related more significantly to physician or treatment delay. It signifies the fact that educated mothers are more observant and concerned about symptoms related to serious diseases whereas educated fathers are more sensitized or resourceful in having timely investigation and treatment. Parental education and socioeconomic level are closely related. Various studies have found that educated parents have better socioeconomic status and can afford treatment in private hospitals where clinical evaluation and diagnostic procedures are done at rapid pace as compared to public sector hospitals. $^{12,13}$

Apart from formal education, parents' perception and knowledge about usefulness of medical treatment in cases of cancer also played a significant role in seeking treatment more promptly. Other studies from developing countries have also mentioned similar results ${ }^{12,14}$

Patient delay was significantly short in younger 
patients (Figure-2). They may experience malignancy with more identifiable signs at onset as compared to older children. Younger age has been the most consistent factor associated with early presentation in studies from different countries. ${ }^{15-20}$ Pollock et al, in a large cohort of 2665 children, found that for all solid tumors except Hodgkin's disease, time delay in diagnosis increased with age. In young children, the aggressive nature of their malignancies may lead to the rapid appearance of symptoms, which shortens the diagnostic delay period. ${ }^{15}$

In our study female gender was not significantly associated with delay. This finding is consistent with some other reports in the literature. Saha et al from United Kingdom found no significant difference in the lag time between males and females. ${ }^{16}$ Abdelkhalek et al from Egypt have reported similar finding. ${ }^{12}$ Begum et al however, have reported a significant correlation between female gender and delayed treatment in Bangladeshi children. ${ }^{14}$

As seen in other studies, type of cancer affects time lag to diagnosis. Acute leukemia and Wilms' tumor were associated with early presentation and Hodgkin lymphoma and brain tumors have been associated with longer delays in presentation and diagnosis. ${ }^{5}$

Our study has certain limitations. It was a small sized, single-center study. Recall bias is a concern, particularly when addressing the beginning of symptoms. Large multicenter studies and national cancer registry are needed to get more comprehensive and reliable information.

\section{CONCLUSION}

Significantly long physician delay is caused by lack of medical facilities in smaller towns, family's socioeconomic status, parental education and perception about usefulness of medical treatment. Better training of medical professionals and improvement in diagnostic facilities in smaller cities can result in reduced time lag before definite treatment. Efforts should be made to promote public and parental awareness about childhood malignancies and benefit of timely management.
Copyright $@ 14$ Nov, 2018.

\section{REFERENCES}

1. Fact Sheets by Population. [Internet]. Available from: http://globocan.iarc.fr/Pages/fact_sheets_population. aspx.

2. Stiller CA, Kroll ME, Pritchard-Jones K. Population survival from childhood cancer in Britain during 1978-2005 by eras of entry to clinical trials. Ann Oncol. 2012;23(9):2464-9. Epub 2012/07/20.

3. Gatta G, Botta L, Rossi S, Aareleid T, Bielska-Lasota M, Clavel J, et al. Childhood cancer survival in Europe 1999-2007: Results of EUROCARE-5--a populationbased study. Lancet Oncol. 2014;15(1):35-47. Epub 2013/12/10.

4. Neal RD, Tharmanathan P, France B, Din NU, Cotton S, Fallon-Ferguson $\mathrm{J}$, et al. Is increased time to diagnosis and treatment in symptomatic cancer associated with poorer outcomes? Systematic review. British Journal of Cancer. 2015;112:S92-S107.

5. Dang-Tan T, Franco EL. Diagnosis delays in childhood cancer: A review. Cancer. 2007;110(4):703-13.

6. Eke GK, Akani NA. Outcome of childhood malignancies at the University of Port Harcourt Teaching Hospital: a call for implementation of palliative care. Afr Health Sci. 2016;16(1):75-82. Epub 2016/07/01.

7. Israels T, Renner L, Hendricks M, Hesseling P, Howard S, Molyneux E. SIOP PODC: recommendations for supportive care of children with cancer in a lowincome setting. Pediatr Blood Cancer. 2013;60(6):899904. Epub 2013/02/27.

8. Ribeiro RC. Improving survival of children with cancer worldwide: the St. Jude International Outreach Program approach. Stud Health Technol Inform. 2012;172:9-13. Epub 2012/08/23.

9. Aliyu UM, Awosan KJ, Oche MO, Taiwo AO, Jimoh AO, Okuofo EC. Prevalence and correlates of complementary and alternative medicine use among cancer patients in usmanu danfodiyo university teaching hospital, Sokoto, Nigeria. Niger J Clin Pract. 2017;20(12):1576-83. Epub 2018/01/31.

10. Sanchez HC, Karlson CW, Hsu JH, Ostrenga A, Gordon C. Complementary and Alternative Medicine Use in Pediatric Hematology/Oncology Patients at the University of Mississippi Medical Center. J Altern Complement Med. 2015;21(11):660-6. Epub 2015/08/25. 
11. Singendonk $M$, Kaspers GJ, Naafs-Wilstra $M$, Meeteren AS, Loeffen J, Vlieger A. High prevalence of complementary and alternative medicine use in the Dutch pediatric oncology population: a multicenter survey. Eur J Pediatr. 2013;172(1):31-7. Epub 2012/09/20.

12. Abdelkhalek E, Sherief L, Kamal N, Soliman R. Factors associated with delayed cancer diagnosis in egyptian children. Clinical Medicine Insights Pediatrics. 2014;8:39-44.

13. Fajardo-Gutiérrez A, Sandoval-Mex AM, Mejía-Aranguré JM, Rendón-Macías ME, Martínez-García MdC. Clinical and social factors that affect the time to diagnosis of Mexican children with cancer. Medical and Pediatric Oncology. 2002;39(1):25-31.

14. Begum M, Islam MJ, Akhtar MW, Karim S. Evaluation of delays in diagnosis and treatment of childhood malignancies in Bangladesh. South Asian Journal of Cancer. 2016;5(4):192-3.

15. Brown BJ, James BO, Ajayi SO, Ogun OA, Oladokun RE. Factors influencing time to diagnosis of childhood cancer in Ibadan, Nigeria. African Health Sciences. 2009;9(4):247-53.
16. Saha V, Love S, Eden T, Micallef-Eynaud P, MacKinlay G. Determinants of symptom interval in childhood cancer. Arch Dis Child. 1993;68(6):771-4. Epub 1993/06/01.

17. Thulesius H, Pola J, Håkansson A. Diagnostic delay in pediatric malignancies--a population-based study. Acta Oncologica (Stockholm, Sweden). 2000;39(7):8736.

18. Haimi M, Peretz Nahum M, Ben Arush MW. Delay in diagnosis of children with cancer: a retrospective study of $\mathbf{3 1 5}$ children. Pediatric Hematology and Oncology. 2004;21(1):37-48.

19. Kassebaum N, Kyu HH, Zoeckler L, Olsen HE, Thomas $\mathrm{K}$, Pinho C, et al. Child and Adolescent Health From 1990 to 2015. JAMA Pediatrics. 2017;171(6):573-92.

20. Pollock $\mathrm{BH}$, Krischer JP, Vietti TJ. Interval between symptom onset and diagnosis of pediatric solid tumors. The Journal of pediatrics. 1991;119:725-32.

21. Cecen E, Gunes D, Mutafoglu K, Sarialiogli F, Olgun $\mathrm{N}$. The time to diagnosis in childhood lymphomas and other solid tumors. Pediatric Blood \& Caner. 2011;57(3):392-7.

\section{AUTHORSHIP AND CONTRIBUTION DECLARATION}

\begin{tabular}{|c|c|c|c|}
\hline Sr. \# & Author-s Full Name & Contribution to the paper & Author $=\mathbf{s}$ Signature \\
\hline 2 & $\begin{array}{l}\text { Tanveer Ashraf } \\
\text { Shoaib Ahmed }\end{array}$ & $\begin{array}{l}\text { Primary author, data collection, } \\
\text { analysis, writing. } \\
\text { Writing. }\end{array}$ & hands \\
\hline 3 & Saman Tanveer & Data collection, Analysis. & Gom an \\
\hline
\end{tabular}

